\title{
Using an Online Nominal Group Technique to Determine Key Implementation Factors for COVID- 19 Vaccination Programmes in Community Pharmacies
}

\section{Dorothee Elsbeth Michel}

Robert Gordon University

\section{Ayesha Iqbal}

University of Nottingham

\section{Laura Faehrmann}

Chamber of Pharmacists Westphalia-Lippe

Ivana Tadić

University of Belgrade: Univerzitet u Beogradu

\section{Ema Paulino}

Ezfy

\section{Timothy F Chen}

The University of Sydney

Joanna C Moullin ( $\nabla$ jcmoullin@gmail.com )

Curtin University https://orcid.org/0000-0002-4103-7569

\section{Research Article}

Keywords: Community pharmacy, Pharmaceutical Care, Pharmacy Practice, Implementation, Nominal Group Technique, Vaccination

Posted Date: June 1st, 2021

DOl: https://doi.org/10.21203/rs.3.rs-556819/v1

License: (c) (1) This work is licensed under a Creative Commons Attribution 4.0 International License. Read Full License

Version of Record: A version of this preprint was published at International Journal of Clinical Pharmacy on October 11th, 2021. See the published version at https://doi.org/10.1007/s11096-021-01335-x. 


\section{Abstract}

Background: One vital strategy to fight the COVID-19 pandemic is the rapid roll-out of vaccination programmes. In a number of countries pharmacists are joining the vaccination programme workforce, including plans to involve community pharmacies in the process.

Objectives: (1) to determine key implementation factors for rapid roll-out of COVID-19 vaccination programmes in European community pharmacies and (2) to test an online approach of the nominal group technique (NGT) to generate ideas and reach consensus to achieve the first aim.

Setting: In February 2021, during a workshop at the 12th Working Conference of the Pharmaceutical Care Network Europe (PCNE).

Methods: An online nominal group technique workshop over 10 hours was conducted. Identified implementation factors were mapped to the Framework for the Implementation of Services in Pharmacy (FISpH) and assessed in terms of importance and changeability.

Main outcome measure: Consensus of key implementation factors.

Results: In total, 85 implementation factors were identified. The top 3 factors were the same for both criteria: (Regular) Staff training on correct vaccination procedure / to perform hands-on injection technique; Training in basic life support / first aid (Cardiopulmonary resuscitation), and; Definition of process, roles and responsibilities in the team.

Conclusion: An online NGT process enabled international collaboration in gathering diverse perspectives on the implementation of COVID-19 vaccination programmes in a time and cost-efficient manner. The process was effective in identifying implementation factors and finding solutions. Online NGT processes may be suitable for other implementation problems, not only during a pandemic.

\section{Impact Of Findings On Practice Statements}

- With appropriate training and support, community pharmacists can deliver critical health services to the public and communities they serve, including mass vaccinations in primary care.

- As the network of community pharmacies is already embedded within primary health care systems, this resource could be used for the rapid roll out of public health services, including mass vaccinations.

- NGT is a suitable method for generating ideas and consensus in a virtual format.

\section{Introduction}

SARS -CoV-2 (COVID-19) emerged in November 2019 and was declared a global health emergency and pandemic by the World Health Organization (WHO) in March 2020 [1, 2]. The virus has since spread 
across parts of the world at an alarming rate and COVID-19 infections are causing significant morbidity and mortality. Many countries are experiencing second and third waves of COVID-19 [3]. Lockdown measures and mass vaccinations can help reduce viral transmission [3]. However, the impact of mass vaccination will depend on the speed and coverage of its roll-out [4].

Utilising existing primary health care, including pharmacists and community pharmacies, is one component of Government policies to expedite mass vaccination programmes $[5,6]$. The involvement of trained pharmacy staff delivering vaccinations in community pharmacies has shown to have a positive impact on public vaccination coverage, for example increasing the reach of annual influenza vaccination programmes $[7,8]$. One advantage of including community pharmacies in vaccination programmes is convenient access to the public due to their geographical spread [5, 6]. As such, engaging community pharmacies and pharmacists into the strategy to provide COVID-19 vaccinations has already been initiated or planned in some countries, including Canada, USA and some European (EU) countries including, Northern Ireland, Italy, Switzerland and the UK [9-20]. To ensure rapid roll-out of COVID-19 vaccination programmes across European community pharmacies, both in terms of widespread uptake by pharmacists and the population, consideration should be given to the implementation factors which may facilitate or hamper the endeavour.

Identifying potential implementation factors during programme development and prior to roll-out can assist the development of tailored implementation strategies, thus reducing the risk of poor uptake and subsequent low reach to the target population [21]. Implementation science bridges the gap between innovation development and evidence gathering (in this case COVID-19 vaccination programmes) and real-world practice [22, 23]. Mapping implementation factors to constructs in an established implementation framework allows better understanding of the different influences and how they may be addressed [24].

In February 2021, at the 12th Working Conference of the Pharmaceutical Care Network Europe (PCNE), a workshop was held to identify factors potentially influencing the implementation of COVID-19 vaccination programmes in EU community pharmacies. The workshop used an adapted online format of the nominal group technique (NGT). NGT is a highly structured consensus method that is widely used in health services research [25]. The technique offers participants the opportunity to discuss ideas freely and to voice their opinion without judgement [26].

This study had two aims (1) to determine key implementation factors for rapid roll-out of COVID-19 vaccination programmes in European community pharmacies and (2) to test an online approach of the nominal group technique. This study was exempt from Ethics approval under Swiss law (Req-202100147, 10.2.2021)

\section{Methods}

\section{Participants}


Participants signed-up for the NGT implementation workshop after registration for the PCNE-Working Conference and were assigned on a first come basis by the conference committee. The workshop group comprised 23 pharmacists from 11 countries, working in a range of settings, with varying levels of clinical, research and implementation expertise (Table 1). The workshop was facilitated by 3 experienced researchers (TFC, JCM, EP).

\section{Online nominal group technique (NGT)}

The NGT was used as an idea generation and consensus method. The NGT has several advantages including time efficiency, cost effectiveness and adaptability. Furthermore, NGT equally considers views of all participants, avoiding one individual dominating the group, and has demonstrated validity [27].

The original NGT consists of 4 steps, namely (1) Silent generation of ideas in writing, (2) Round-robin feedback from group members to record each idea (3) Discussion of each recorded idea for clarification and evaluation, (4) Individual voting on priority ideas [28].

The NGT has been adapted and expanded including for priority setting of evidence-practice gaps in implementation science [27]. Further adaption to the NGT occurred for this study. Due to the COVID-19 pandemic the conference, including the workshops, were conducted in an online format via Zoom ${ }^{\circledR}$ software. The workshop time frame was for 5 two-hour sessions ( 10 hours in total), over 3 days. Thus, the online format and time constraints required adaptations to the NGT method to make it more flexible and feasible online (Fig. 1).

At the opening workshop session ( 2 hours) the participants received an introduction to implementation science and practice. This introduction focused on the Generic Implementation Framework (GIF) and Framework for the Implementation of Services in pHarmacy (FISpH) $[29,30]$. Background literature regarding COVID-19 vaccines and NGT and its adapted online format were also presented. Following the general introduction participants were purposively assigned based on their knowledge and experience with implementation science into 4 smaller groups, in accordance with a team-based learning approach [31]. At the end of the opening session a preliminary research question was presented, which was discussed and refined by the whole group. The final research question was: What are the factors required for the implementation of a rapid roll out of a COVID-19 vaccination strategy during a community pharmacy delivery phase in the EU? 3 assumptions were made: (1) vaccination in community pharmacies is legally allowed, (2) vaccine supply is ensured and (3) vaccine requires normal cool storage (2-8 ${ }^{\circ}$ Celsius).

The next 4 workshop sessions ( 8 hours in total) were used to conduct the steps of the NGT in an online format (Fig. 1). During the first step ("Generating implementation factors"), participants individually brainstormed the factors that may influence the implementation process of a COVID-19 vaccination program in community pharmacies in the EU. The aim of this step was to generate as many ideas as possible thinking across the phases of the implementation process. 
The 2nd step ("Recording implementation factors") included round robin feedback sessions within participants' four smaller breakout groups to discuss and concisely record each factor. Each factor was recorded so that they were independent of each other without multiple clauses. Groups listed their implementation factors in a spreadsheet (MS Excel) for collation by the moderator. The moderator (EP) distilled statements into individual factors and removed duplicates.

The 3rd step of the online NGT ("Clarifying and distilling implementation factors") involved the moderator and participants clarifying any factors for which they were unsure of the meaning or whether they constituted duplicates. A final version of the list was provided to all participants.

At the 4th step ("Individuals rate the importance and changeability of factors") participants were asked to rate the relative importance and changeability of each factor of the compiled list using a Likert-type scale from 1 to 5 , with 5 being the most important or changeable. This step was used to ensure that each participant had read and considered each implementation factor in detail prior to group discussion and consensus.

During step 5 of the online NGT ("Prioritisation of implementation factors"), each participant prioritised 5 implementation factors for the criteria "importance" and "changeability".

Step 6 ("Rating group discussion") began with discussions in smaller groups about each member's individual prioritised implementation factors. Participants shared their ratings, speaking in turn to list their top 5 for each criterion (importance and changeability) and provide any clarification for their choices.

During step 7 ("Reaching group consensus"), the breakout groups re-convened as one large group to review and discuss the implementation factor ratings, resolve any differences and reach consensus about the five most important and most changeable implementation factors.

At the end of the workshop all participants provided verbal consent to receive an invitation by email to an online survey to collect data about demographics and professional experience. The survey contained items related to age, gender, professional experience, country of residence, prior expertise with NGT / implementation science and vaccination in community pharmacy. The survey was designed as a google form and a link was sent to all participants via email.

Post-conference data analysis:

The Framework for the Implementation of Services in pHarmacy (FISpH) was used to code the identified implementation factors [30]. The FISpH is based on pharmacy practice research and 2 other implementation frameworks adapted for pharmacy practice, namely the Consolidated Framework for Implementation Research (CFIR) and the Theoretical Domains Framework (TDF) [32, 33]. All identified implementation factors were mapped independently by 2 authors (DM and Al) whilst striving to avoid double-coding. These factors were considered within a European context, where in many countries 
activities like training and marketing are provided at the system level. Any discrepancies in coding were resolved by thorough discussion. A 3rd coder (JCM) checked for consistency.

The final scoring results for each factor on importance and changeability given by the small groups were presented in Tables 3 and 4.

Demographic data of participants were presented using descriptive statistics (frequencies, mean, standard deviation, and range). Microsoft Office Excel 10 and Statistical Package for Social Sciences (SPSS) (SPSS v.20; SPSS Inc, Chicago, IL, USA) were used for data analysis.

\section{Results}

\section{Study sample}

23 participants signed up for the online workshop held at the 12th PCNE-Working Conference.

Participants were from 11 different countries with expertise in pharmacy (research and/or clinical practice). All participants, except one filled in the online survey on participants' basic characteristics. The basic characteristics of 22 participants are presented in Table 1. 


\section{Gender, n (\%)}

Female

Male

\section{Country of residence, $n$ (\%)}

Australia 1

Belgium 2

Denmark 2

Germany 4

Norway 1

Slovenia 1

Serbia 3

Switzerland 6

The Netherlands 1

United Kingdom 1

Professional expertise, $\mathbf{n}(\%)$

Academia

Community pharmacy

Academia and Community pharmacy

Hospital pharmacy

Professional organisation (e.g. pharmacy chamber, national pharmacy board)

\section{Prior experience with NGT, $n$ (\%)}

Used it before

Read about it

No experience

Familiarity with implementations methods and strategies, $\mathrm{n}(\%)$ 
Worked in this field

Read about it

Not familiar

Is vaccination in community pharmacies legal (in participants' country of residence)?, $\mathrm{n}(\%)$

Yes

No

Currently under development

$6(27.3)$

Have you ever been vaccinated in a community pharmacy? n (\%)

Yes

No

Have you ever vaccinated a patient?, $\mathrm{n}(\%)$

Yes

No

$19(86.4)$

\section{Identified implementation factors}

Individual brainstorming yielded 160 implementation factors. After removal of duplicates 85

implementation factors remained. These implementation factors were mapped to the FISpH as shown in Table 2 [30]. Implementation factors pertaining to the organisational/pharmacy level were most frequent $(n=32)$, followed by implementation factors relating to the wider external setting $(n=22)$, the local setting $(n=16)$, characteristics of individuals involved in the implementation of the service $(n=10)$ and finally factors relating to the intervention characteristics [the vaccination programme] $(n=5)$. 
Table 2

Implementation factors

FISpH construct*

Implementation factors

\section{Innovation (vaccination programme) factors}

Implementation

complexity

Design quality \& packaging

Nature of innovation

Vaccine prescription

Staff reorganisation e.g. hiring more staff

\section{External system}

Remuneration

Remuneration to set-up/prepare for service implementation

Healthcare budget \&

Remuneration for the service (by government, patients or other sources / contracts third party payers)

Interprofessional networks \& Inter professional recognition (system level recognition and acceptance by other professionals) communication

Stakeholder buy-in

Support of the national pharmacy organisation(s)

Acknowledgement of the pharmacists a health care provider from other healthcare providers who may also participate in vaccination

External support and / or assistance

Advertisement/ public announcements/ recommendation on vaccination in pharmacies

Guidelines / SOPs from national pharmacy organisation

Strategy in case of an emergency

Clarification on insurance for staff

Telephone helpline for patients (nationwide)

Information on vaccination strategy (voucher/sheet/appointment card)

Information on vaccination status / vaccination passport (access to online patient record / tool of health care system)

(Regular) Staff training on correct patient risk assessment for vaccination

Appointment system (online booking of vaccination time slots for citizens)

* FISpH Framework for the Implementation of Services in pHarmacy (Moullin 2016) 
Administrative support to identify patients belonging to a certain priority group

Information and measures for a hygiene concept (guidelines)

(Regular) Staff training on correct vaccination procedure / to perform hands-on injection technique

(Regular) Staff training on correct monitoring procedures after vaccination

Training in vaccine centres prior to local pharmacy vaccination

Training in handling side effects

Training in basic life support / first aid (Cardiopulmonary resuscitation)

Material for vaccination (needles)

\section{Local Setting}

Intraprofessional

network \&

Collaboration on the task within smaller pharmacies

communication

\& communication
Interprofessional network

Availability to communicate with other healthcare (GPs) in situations where it is necessary

Referral from other health care professionals (local)

Support from other health care professionals

Community's perception about innovation and organisation

Patient awareness of the service
Clear arrangements in the community (clear direction in the community)

Patient acceptance for vaccination (local population beliefs)

Patients' trust for service in the pharmacy

The pharmacy is easily accessible by the patient/ Community pharmacy location in terms of accessibility (physical location)

Local demand

Active recruitment of patients

Community pharmacist timings need to be accounted especially and should be accessible beyond school and office hours

Patients' satisfaction with the service

Relatively short waiting time (patient perspective of getting in CP)

* FISpH Framework for the Implementation of Services in pHarmacy (Moullin 2016) 
FISpH construct*

Patient needs \& resources/Organisational

factor: Data

management system

Peer pressure

External pressure for broad provision of the vaccination
Documentation on vaccination / reminder for patient

\section{Implementation factors}

\section{Organisation (pharmacy) Factors}

Structural characteristics

Staff

Layout \& workflow
Waiting facilities need to be considered especially when administering to older people

Number of pharmacists and technicians (and enough skilled and trained staff)

Staff, including technicians, nurses, pharmacists, students (medicine, pharmacy)

\section{Limited pharmacy workforce}

Room/Space for vaccination (external flat/containers/office spaces/hotels)

Community pharmacy infrastructure should support administering in private consultation room / appropriate space within the pharmacy to perform vaccination

Availability of the waiting area/observation area/space (inside)

Provision of social distancing measures (inside)

Hygiene concept (general for the vaccination site; separation from infected people)

Preparation area (laboratory)- workflow (inside)

Waste removal

Teamwork

Definition of process, roles and responsibilities in the team

Readiness for implementation

Leadership engagement

Available resources and training
Rearrange internal workflow (compatibility of intervention to existing systems)-

Head of pharmacy/ pharmacy manager acceptance

Availability of internet / telephone / documentation to report the adverse drug reactions

Long opening hours in pharmacies

Software to register vaccination to link to national surveillance system

Correct storage of vaccines at pharmacy (stock)

* FISpH Framework for the Implementation of Services in pHarmacy (Moullin 2016) 
Implementation factors

Storage space and equipment (fridge), for open vial

Material for hygiene / safety

Material for emergencies

(Lack of) Time

Access to knowledge and information

Data management system
Availability of software / literature for drug-drug interactions

FAQ sheet/database for pharmacy staff

Access to central database to view and record patient and intervention data / availability of the medication patients records in order to review the health condition of the patients and history of previous illness (including COVID)

Follow up of patients for second dose

Inclusion and exclusion criteria for vaccination (risk factors) (check list and priority lists)

Collection of additional data (drug information) post marketing

Environmental stressors Workload

Organisational support Clear information at the pharmacy on when, how and why to be and assistance vaccinated

$\&$

Access to knowledge and information

Organisational support Social media and assistance

Experience Previous community pharmacy experience with vaccination (i.e. flu)

\section{Individual (pharmacist and other pharmacy staff) factors}

General knowledge

Knowledge about the innovation
Knowledge about patient target group

Pharmacy staff knowledge (pharmacists and technicians) education about immunization with different types of vaccines (indications, contraindications, adverse drug reactions)

Beliefs about the innovation

Technical skills (experience, capacity \& competence)
Concerns about adverse events by pharmacy staff

Staff identifying eligible patients

Expertise in recognized inclusion and exclusion criteria for vaccination (risk factors) /check list

* FISpH Framework for the Implementation of Services in pHarmacy (Moullin 2016) 


\begin{tabular}{|ll|}
\hline FISpH construct* & Implementation factors \\
\hline $\begin{array}{l}\text { Interpersonal skills } \\
\text { (experience, capacity \& } \\
\text { competence) }\end{array}$ & $\begin{array}{l}\text { Patient counselling about vaccination } \\
\text { Community pharmacists' patient dealing skills (social skills) in order to } \\
\text { help minimize vaccine / injection fear / reluctance } \\
\text { Communications skills of pharmacists }\end{array}$ \\
\hline Values \& motivation & \begin{tabular}{l} 
Staff acceptance / willingness \\
\cline { 2 - 2 }
\end{tabular} \\
\hline * FiSpH Framework for the Implementation of Services in pHarmacy (Moullin 2016) \\
\hline
\end{tabular}

Table 3 lists 14 implementation factors that were deemed important, and Table 4 lists 13 implementation factors deemed changeable by the 4 groups. 6 implementation factors were ranked as important and as changeable. The top 3 factors in terms of importance and changeability were the same for both criteria. These were: (1) (Regular) Staff training on correct vaccination procedure / to perform hands-on injection technique; (2) Training in basic life support / first aid (Cardiopulmonary resuscitation), and; (3) Definition of process, roles and responsibilities in the team. In addition, (4) Hygiene concept (general for the vaccination site; separation from infected people); (5) (Regular) Staff training on correct patient risk assessment for vaccination and; (6) Room/Space for vaccination (external flat/containers/office spaces/hotels) were considered both as important and changeable. 
Table 3

Implementation factors ranked by importance

Implementation factors: Importance

(Regular) Staff training on correct vaccination procedure / to perform hands-on injection technique*

Training in basic life support / first aid (Cardiopulmonary resuscitation) *

Definition of process, roles and responsibilities in the team*

Room/Space for vaccination (external flat/containers/office spaces/hotels) *

Pharmacy workforce

Information on vaccination status: Vaccination Passport (or access to online tool of health care system)

Appointment system (online booking of vaccination time slots for citizens)

(Regular) Staff training on correct patient risk assessment for vaccination*

Staff, including technicians, nurses, pharmacists, students (medicine, pharmacy)

Hygiene concept (general for the vaccination site; separation from infected people) *

Patient acceptance for vaccination (local population beliefs)

(Regular) Staff training on correct monitoring procedures after vaccination

Remuneration to set-up/prepare for service implementation

Inclusion and exclusion criteria for vaccination (risk factors) - check list and priority lists

FISpH constructs

External support and/or assistance

External support and/or assistance

Teamwork

Layout \& workflow

32

Staff

4

External support and/or assistance

External support and/or assistance

External support and/or assistance

Staff

Layout \& workflow

Community's perception

about innovation and

organisation

External support and/or assistance

Remuneration 1

Quality assurance system

Note: 5 indicates highest, 1 indicates lowest importance; implementation factors without a ranking number were considered less important by the respective groups.

* Indicates factors that were rated as high importance and changeability 
Implementation factors ranked by changeability

\section{Implementation factors: Changeability}

(Regular) Staff training on correct vaccination procedure / to perform hands-on injection technique*

Training in basic life support / first aid (Cardiopulmonary resuscitation) *

Definition of process, roles and responsibilities in the team *

Provide information/leaflets to patients about possible ADR and instructions what/where to report

Hygiene concept (general for the vaccination site; separation from infected people) *

Patient awareness of the service

FAQ sheet / database for pharmacy staff

(Regular) Staff training on correct patient risk assessment for vaccination *

Expertise in recognised inclusion and exclusion criteria for vaccination (risk factors) - check list

Software to register vaccination to link to national surveillance system

Follow up of patients for 2 nd dose

Storage space (fridge), open vial

Room/Space for vaccination (external flat/containers/office spaces/hotels) *
FISpH constructs

External support and/or assistance

External support and/or assistance

Teamwork

Design quality \& packaging

2

3

1

22

A $\quad$ B $\quad$ C $\quad$ D

$\begin{array}{llll}5 & 3 & 5 & 5\end{array}$

3

4

22

23

3

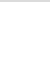

Layout \& workflow

Community's perception about innovation and organisation

5

Access to knowledge and

4 information

External support and/or assistance

4

Technical skills (experience, capacity \& competence)

Available resources and training

Data management system

1

Available resources and training

Layout \& workflow 1

Note: 5 indicates highest, 1 indicates lowest changeability. Implementation factors without a ranking number were considered less changeable by the respective groups.

* Indicates factors that were rated as high importance and changeability

In total, 6 of the 14 implementation factors rated in the participants top 5 factors for importance were related to "External support and/or assistance". "Remuneration" was an additional implementation factor 
rated as important at the external system level. 6 implementation factors related to pharmacy/organisational level, with the final factor being at the local setting level related to the community/patients' perception or acceptance of the vaccination programme. On the contrary, in terms of changeability only 3 implementation factors were related to the external system (all coded as "external support and/or assistance"), while 7 were at the pharmacy/organisational level (coded within "available resources and training", "data management system", "teamwork", "layout \& workflow"), and one factor related to the innovation ("Design quality and packaging"), the individual/staff level ("technical skills" (experience, capacity \& competence)) and local setting (community/patients' perception or acceptance of the vaccination programme) respectively (Table 5).

Table 5

Spread of implementation factors across FISpH domains

\begin{tabular}{|lll|}
\hline Rating criterion & Important & Changeable \\
\hline Innovation (vaccination programme) & - & 1 \\
\hline Individual (staff) & - & 1 \\
\hline Organisation (pharmacy) & 6 & 7 \\
Local Setting & 1 & 1 \\
\hline External System & 7 & 3 \\
\hline
\end{tabular}

\section{Discussion}

Several implementation factors must be considered to enable successful implementation of COVID-19 vaccination programmes in community pharmacy. These factors can help decision makers to decide and prioritise implementation strategies during the implementation process. Factors can present as barriers or facilitators depending upon the country's unique health care systems. As such, it is essential each country contextualises the implementation factors for their own setting to develop evidence-based implementation strategies.

To decide on the most important and most changeable implementation factors for a COVID-19 vaccination programme in EU community pharmacies, a workshop was performed at the PCNE Working Symposium in February 2021. Key implementation factors identified by the 23 workshop participants from 11 different countries were related to staff training in vaccination, staff training in basic life support (in case of adverse events), and workflow of the pharmacy.

As pharmacists are not currently providing vaccines across all EU countries, training to ensure pharmacy staff have sufficient capability and capacity is necessary. Trainings could be performed combining online material and demonstration videos along with face-to-face practicum on the application procedure [34]. Pharmacy staff must also be prepared to deal with anaphylactic events due to injection reactions and thus ensure patient safety $[34,12,35]$. In this study "staff training" was identified as the most important 
and changeable implementation factor. It is interesting to note, "Staff training" can be considered as either an organisational or internal factor, if such training would be delivered within a pharmacy or pharmacy chain, or a system or external factor, if a professional organisation or national body were to develop and deliver such training. Implementation science acknowledges the fluidity of constructs across contexts and that the interface between inner and outer setting is dynamic [36].

Besides the practical skills and knowledge, it is essential the vaccination service is integrated into the workflow of the pharmacy including defining roles and responsibilities within the team. As pharmacies implement COVID-19 vaccination programmes, there will be additional workload including logistics, storage, and appointment management. The FIP has developed a guidance document detailing these aspects with regard to vaccination programmes in community pharmacy in general [37].

This study highlights implementation factors, which require corresponding implementation strategies in EU countries. However, the NGT process and findings may be useful for other countries. This study provides a list of potential implementation factors, which may help to develop, improve, and revisit strategies for new and existing COVID-19 vaccination programmes. It may also assist in post-evaluation implementation research of COVID-19 vaccination programmes in countries where the vaccine(s) have already been rolled out in community pharmacies.

\section{Adaptation of an online NGT process}

While NGT has been employed for a range of health care questions it is usually associated with face-to face meetings [38-40]. However, an online approach can reach the same quality of outcomes [41]. In this study the online NGT facilitated the collaboration of international participants during a global pandemic and enabled consensus on the key implementation factors. Video conferencing together with expert facilitation meant communication and discussion flowed easily. During the online NGT, all participants had a chance to express their opinion equally and therefore objective conclusions emerged. Group consideration of individual ideas made this method transparent. To standardise the process, the NGT steps as outlined were followed with spreadsheets documenting the progress. In addition, the online process was both time and cost efficient as participants were not required to travel which is particularly advantageous and pronounced when international collaboration is desired [27].

\section{Strengths And Limitations}

A strength of this study was the diverse participant group. The workshop was attended by participants from 11 countries, with backgrounds across academia, a range of clinical practices, and professional organisations, which provided a rich distribution of perspectives and factors. The diverse group could also be seen as a limitation as implementation factors are context dependent, particularly their importance and changeability. In addition, as discussed, factors may be situated and addressed by different levels of the system depending on the context. 
A further strength and limitation of the study, and NGT in general, is the necessity for the research question to be specific and narrow to produce meaningful results. Hence, the research question focused only on vaccines stored between $2-8^{\circ} \mathrm{C}$, programmes that take place in community pharmacies in Europe and assumes countries have the legislation in place for vaccination programmes to occur in community pharmacies. To be inclusive of Low- and Middle-Income Countries would have resulted in a list of implementation factors that would have been too broad to be useful. We recommend the process is repeated for these settings.

Due to time constraints and time zone differences, only brief periods of time were possible for collation, clarification, removal of duplicate items, and prospective classification of items under an implementation framework. Additional time to ensure consistent wording of implementation factors would have been beneficial. Furthermore, due to time, final group consensus on the 5 most important and changeable factors was not reached by discussion, but rather was appraised by the 4 sub-group ratings. A factor was considered as overall important or changeable if either a high rate was given by one group, which depicts the importance of the factor for that particular group, or if multiple groups selected the factor [42].

Finally, when the authors were mapping the implementation factors to the respective constructs in the FISpH it became clear that due to the European context of this project more differentiation in the external system of FISpH would be useful. The FISpH was originally developed using practice research in Australia where external influences on service implementation in community pharmacies are less dominant. For example, it would be valuable if the construct "external support and / or assistance" was subdivided into "regional pharmacy chambers", "national pharmacy board" and "owners' associations".

\section{Conclusion}

An online NGT process enabled international collaboration in gathering diverse perspectives on the implementation of COVID-19 vaccination programmes in a time and cost-efficient manner. The process was effective in identifying implementation factors and finding solutions. Online NGT processes may be suitable for other problems, not only during a pandemic.

\section{Declarations}

\section{Funding:}

No funding was received for this study. The work of Ivana Tadic was partially supported by the Ministry of Education, Science and Technological Development of Republic of Serbia (project No. 451-03-9/202114/200161).

\section{Conflicts of interest/Competing interests:}

The authors declare no conflicts of interest. 


\section{Authors' contributions:}

EP, TFC and JCM designed the study and facilitated the workshop. DM and Al conducted the thematic coding, which was endorsed by JCM. DM, Al, LF, IT drafted the manuscript. All authors read and edited the final manuscript.

\section{Ethics approval:}

The project was exempt from Ethics approval as clarified by the Ethics Committee Northwest and Central Switzerland (Req-2021-00147; 10.2.2021)

\section{Consent to participate:}

Verbal consent was obtained from all workshop participants.

\section{Consent for publication:}

Verbal consent for publication of the workshop process and results was obtained from workshop participants. Participants were sent the final manuscript draft for comment.

\section{Acknowledgements:}

We would like to thank Pia M. Schumacher, Germany, for her support in drafting the manuscript. We would also like to acknowledge the other participants of Workshop 3 at the 12th PCNE Working Conference 2021: Agnieszka Moszczynski, Poland; Eyob Alemayehu Gebreyohannes, Australia; Fabienne Boeni, Switzerland; Hege Salvesen Blix, Norway; Lea Knez, Slovenia; Léa Boden, Switzerland; Markus Messerli, Switzerland; Marle Gemmeke, The Netherlands; Michael Ceulemans, Belgium; Milena Kovacevic, Serbia; Pascal Baumgartner, Switzerland; Ramune Jacobsen, Denmark; Sandra Vezmar Kovacevic, Serbia; Sophie Du Pasquier, Switzerland; Tamara Imfeld-Isenegger, Switzerland; Trine R. H. Andersen, * Denmark; Veerle Foulon, Belgium; Viktoria Sophie Wurmbach, Germanywith an asterix if they are PCNE members). *PCNE members

\section{References}

1. Spychalski P, Błażyńska-Spychalska A, Kobiela J. Estimating case fatality rates of COVID-19. The Lancet Infectious Diseases. 2020; https://doi.org/10.1016/S1473-3099(20)30246-2

2. Ou X, Liu Y, Lei X, Li P, Mi D, Ren L, Guo L, Guo R, Chen T, Hu J, Xiang Z, Mu Z, Chen X, Chen J, Hu K, Jin Q, Wang J, Qian Z. Characterization of spike glycoprotein of SARS-CoV-2 on virus entry and its immune cross-reactivity with SARS-CoV. Nature communications. 2020; https://doi.org/10.1038/s41467-020-15562-9

3. Graichen H. What is the difference between the first and the second/third wave of Covid-19? German perspective. Journal of orthopaedics. 2021; https://doi.org/10.1016/j.jor.2021.01.011 
4. Schaffer DeRoo S, Pudalov NJ, Fu LY. Planning for a COVID-19 Vaccination Program. JAMA. 2020; https://doi.org/10.1001/jama.2020.8711

5. Goold SD. Trust, distrust and trustworthiness. Journal of general internal medicine. 2002; https://doi.org/10.1046/j.1525-1497.2002.11132.x

6. Birkhäuer J, Gaab J, Kossowsky J, Hasler S, Krummenacher P, Werner C, Gerger H. Trust in the health care professional and health outcome: A meta-analysis. PloS one. 2017; https://doi.org/10.1371/journal.pone.0170988

7. International Pharmacist Federation (FIP). An overview of pharmacy`s impact on immunisation coverage: A global survey.

https://www.fip.org/files/fip/publications/FIP_report_on_Immunisation.pdfInternational Pharmacist Federation (FIP). 2020. Accessed 16 May 2021.

8. Patel RS, Bachu R, Adikey A, Malik M, Shah M. Factors Related to Physician Burnout and Its Consequences: A Review. Behavioral sciences (Basel, Switzerland). 2018;

https://doi.org/10.3390/bs8110098

9. Government of Ontario. COVID-19 pharmacy vaccine locations. https://covid-19.ontario.ca/vaccinelocationsGovernment of Ontario. 2021. Accessed 15 Apr 2021.

10. Alberta Blue Cross. COVID-19 Immunization Program. https://www.ab.bluecross.ca/news/covid-19immunization-program-information.phpAlberta Blue Cross. 2021. Accessed 15 Apr 2021.

11. Australian Government Department of Health. COVID-19 Vaccination. https://www.health.gov.au/initiatives-and-programs/covid-19-vaccines/information-for-covid-19vaccination-providersAustralian Government Department of Health. 2021. Accessed 15 Apr 2021.

12. Centers for Disease and Prevention (CDC). Pharmacies Participating in COVID-19 Vaccination. https://www.cdc.gov/vaccines/covid-19/retail-pharmacy-program/participatingpharmacies.htmlCenters for Disease and Prevention (CDC). 2021. Accessed 15 Apr 2021.

13. Pharmaceutical Group of European Union (PGEU). Insights from community pharmacists in the frontline. https://www.pgeu.eu/insights-from-community-pharmacists-in-thefrontline/Pharmaceutical Group of European Union (PGEU). 2021. Accessed 15 Apr 2021.

14. International Pharmaceutical Federation (FIP). FIP Covid-19 Information Hub. https://www.fip.org/coronavirus\#vaccinelnternational Pharmaceutical Federation (FIP). 2021. Accessed 15 Apr 2021.

15. Gouvernement.fr. info coronavirus COVID 19 - Vaccins. https://www.gouvernement.fr/infocoronavirus/vaccinsGouvernement.fr. 2021. Accessed 15 Apr 2021.

16. Laurent P. CJ. sortiraparis. Covid: Over 18,000 pharmacies registered to give AstraZeneca vaccine. https://www.sortiraparis.com/news/coronavirus/articles/242571-covid-over-18000-pharmaciesregistered-to-give-astrazeneca-vaccine/lang/ensortiraparis. Accessed 16 May 2021.

17. Pharmacy Magazine. Two-thirds of pharmacies in Northern Ireland giving Covid jabs. Pharmacy Magazine. 2021. Accessed 15 Apr 2021. 
18. ANSA.it. COVID-19 vaccinations in pharmacies get under way - English. https://www.ansa.it/english/news/general_news/2021/03/30/covid-19-vaccinations-in-pharmaciesget-under-way_036a6f37-036e-4b06-ad59-f56ebabd09f6.htmIANSA.it. 2021. Accessed 15 Apr 2021.

19. PMLive. UK pharmacies to begin administering COVID-19 vaccinations. http://www.pmlive.com/pharma_news/uk_pharmacies_to_begin_administering_covid19_vaccinations_1361373PMLive. 2021. Accessed 15 Apr 2021.

20. pharmaSuisse. Impfapotheken. https://impfapotheke.ch/pharmaSuisse. Accessed 21.05.2021.

21. Theobald S, Brandes N, Gyapong M, El-Saharty S, Proctor E, Diaz T, Wanji S, Elloker S, Raven J, Elsey $\mathrm{H}$, Bharal S, Pelletier D, Peters DH. Implementation research: new imperatives and opportunities in global health. The Lancet. 2018; https://doi.org/10.1016/S0140-6736(18)32205-0

22. Peters DH, Adam T, Alonge 0 , Agyepong IA, Tran N. Implementation research: what it is and how to do it. BMJ. 2013; https://doi.org/10.1136/bmj.f6753

23. Eccles MP, Mittman BS. Welcome to Implementation Science. Implementation science : IS. 2006; https://doi.org/10.1186/1748-5908-1-1

24. Nilsen P. Making sense of implementation theories, models and frameworks. Implementation science : IS. 2015; https://doi.org/10.1186/s13012-015-0242-0

25. Cantrill JA, Sibbald B, Buetow $S$. The Delphi and nominal group techniques in health services research. International Journal of Pharmacy Practice. 2011; https://doi.org/10.1111/j.20427174.1996.tb00844.x

26. McMillan SS, King M, Tully MP. How to use the nominal group and Delphi techniques. International journal of clinical pharmacy. 2016; https://doi.org/10.1007/s11096-016-0257-x

27. Rankin NM, McGregor D, Butow PN, White K, Phillips JL, Young JM, Pearson SA, York S, Shaw T. Adapting the nominal group technique for priority setting of evidence-practice gaps in implementation science. BMC medical research methodology. 2016; https://doi.org/10.1186/s12874-016-0210-7

28. Delbecq AL, van de Ven AH, Gustafson DH. Group techniques for program planning. Glenview, III.: Scott Foresman and Co; 1975.

29. Moullin JC, Sabater-Hernández D, Fernandez-Llimos F, Benrimoj SI. A systematic review of implementation frameworks of innovations in healthcare and resulting generic implementation framework. Health research policy and systems. 2015; https://doi.org/10.1186/s12961-015-0005-z

30. Moullin JC, Sabater-Hernández D, Benrimoj SI. Model for the evaluation of implementation programs and professional pharmacy services. Research in social \& administrative pharmacy : RSAP. 2016; https://doi.org/10.1016/j.sapharm.2015.08.003

31. Michaelsen LK, Sweet M. Team-based learning. New Directions for Teaching and Learning. 2011; https://doi.org/10.1002/tl.467

32. Damschroder LJ, Aron DC, Keith RE, Kirsh SR, Alexander JA, Lowery JC. Fostering implementation of health services research findings into practice: a consolidated framework for advancing implementation science. Implementation science : IS. 2009; https://doi.org/10.1186/1748-5908-4-50 
33. Michie S, Johnston M, Abraham C, Lawton R, Parker D, Walker A. Making psychological theory useful for implementing evidence based practice: a consensus approach. Quality \& safety in health care. 2005; https://doi.org/10.1136/qshc.2004.011155

34. Lau ETL, Rochin ME, DelDot M, Glass BD, Nissen LM. "There's No Touching in Pharmacy": Training Pharmacists for Australia's First Pharmacist Immunization Pilot. The Canadian Journal of Hospital Pharmacy. 2017.

35. Centers for Disease and Prevention (CDC). Management of Anaphylaxis at COVID-19 Vaccination Sites | CDC. https://www.cdc.gov/vaccines/covid-19/clinical-considerations/managinganaphylaxis.htmlCenters for Disease and Prevention (CDC). Accessed 18 May 2021.

36. Lengnick-Hall R, Stadnick NA, Dickson KS, Moullin JC, Aarons GA. Forms and functions of bridging factors: specifying the dynamic links between outer and inner contexts during implementation and sustainment. Implementation science : IS. 2021; https://doi.org/10.1186/s13012-021-01099-y

37. International Pharmacist Federation (FIP). Give it a shot: Expanding immunisation coverage through pharmacists. www.fip.org/file/4699International Pharmacist Federation (FIP). 2020. Accessed 16 May 2021.

38. Allen J, Dyas J, Jones M. Building consensus in health care: a guide to using the nominal group technique. British journal of community nursing. 2004; https://doi.org/10.12968/bjcn.2004.9.3.12432

39. Newlands RS, Power A, Young L, Watson M. Quality improvement of community pharmacy services: a prioritisation exercise. International Journal of Pharmacy Practice. 2018; https://doi.org/10.1111/ijpp.12354

40. Hermansyah A, Pitaloka D, Sainsbury E, Krass I. Prioritising recommendations to advance community pharmacy practice. Research in social \& administrative pharmacy : RSAP. 2018; https://doi.org/10.1016/j.sapharm.2018.02.003

41. Lago PP, Beruvides MG, Jian J-Y, Canto AM, Sandoval A, Taraban R. Structuring group decision making in a web-based environment by using the nominal group technique. Computers \& Industrial Engineering. 2007; https://doi.org/10.1016/j.cie.2006.11.003

42. McMillan SS, Kelly F, Sav A, Kendall E, King MA, Whitty JA, Wheeler AJ. Using the Nominal Group Technique: how to analyse across multiple groups. Health Services and Outcomes Research Methodology. 2014; https://doi.org/10.1007/s10742-014-0121-1

\section{Figures}




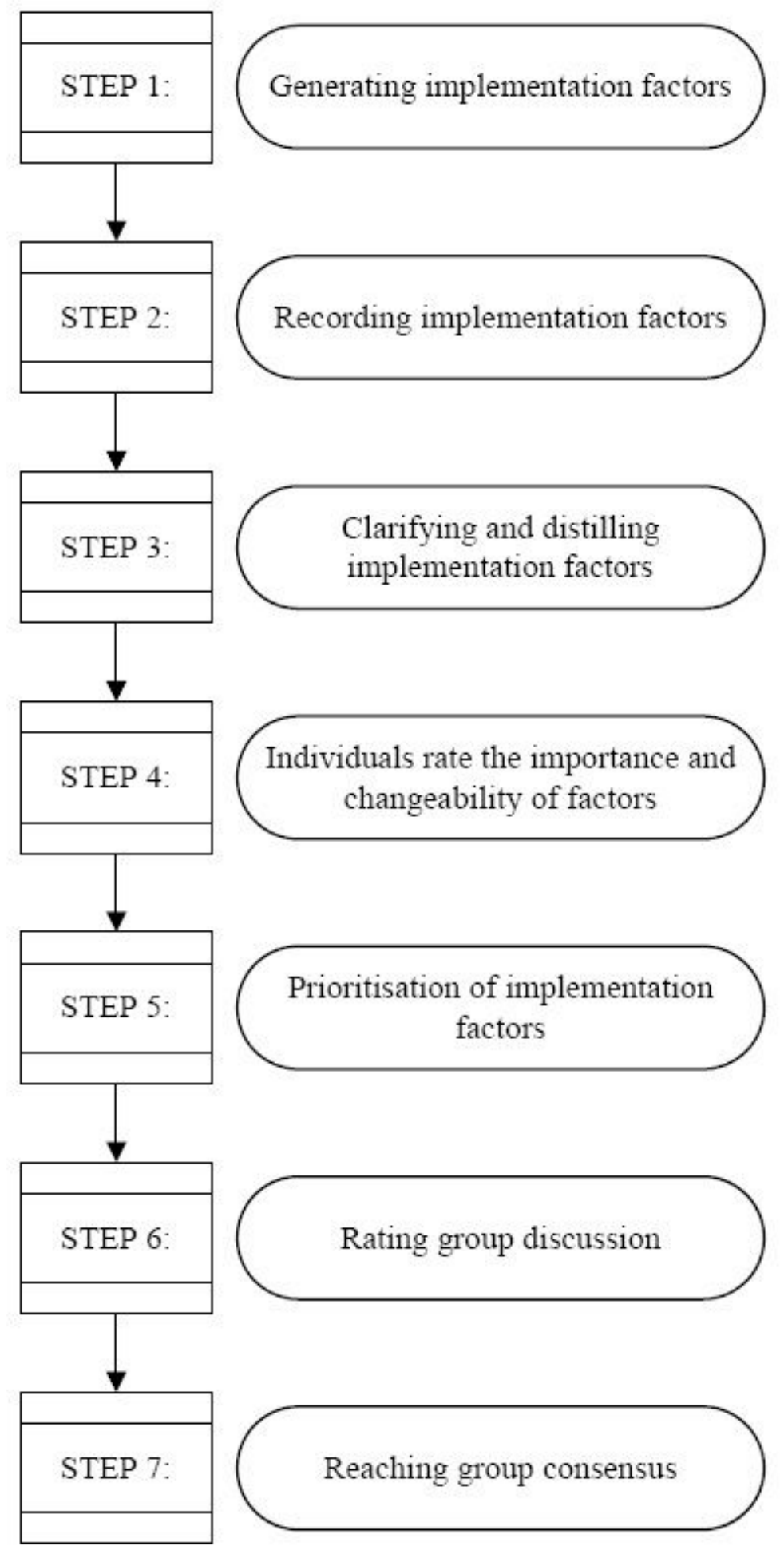

\section{Figure 1}

Flow chart of the conducted online NGT 